\title{
PENERAPAN FORWARD CHAINING UNTUK MENINGKATKAN KEMAMPUAN MEMAKAI BAJU PADA ANAK PENYANDANG DISABILITAS INTELEKTUAL SEDANG
}

\author{
Natasya $^{1}$, dan Stella Tirta ${ }^{2}$ \\ ${ }^{1}$ Fakultas Psikologi, Universitas Tarumanagara Jakarta \\ Email: natasya.juandi@gmail.com \\ ${ }^{2}$ Fakultas Psikologi, Universitas Tarumanagara Jakarta \\ Email: stella.tirta@gmail.com
}

\begin{abstract}
ABSTRAK
Anak dengan disabilitas intelektual memiliki keterampilan bina diri yang lebih rendah dari anak seusianya. Penguasaan keterampilan bina diri, seperti keterampilan mengenakan pakaian secara mandiri merupakan komponen penting yang harus dikuasai anak untuk dapat berpartisipasi aktif dalam kegiatan akademik maupun kegiatan sosial. Anak dengan disabilitas intelektual seringkali mengalami kesulitan untuk menentukan bagian depan dan belakang pakaian, dan akhirnya mengenakan pakaian secara terbalik. Oleh sebab itu, diperlukan teknik modifikasi perilaku yang dapat meningkatkan kemampuan anak dengan disabilitas intelektual dalam mengenakan pakaian dengan benar. Teknik modifikasi ini akan berfokus pada pengembangan keterampilan mengenakan baju kaus. Teknik modifikasi perilaku yang diterapkan adalah forward chaining. Forward chaining membantu anak untuk belajar mengenakan baju dengan urutan yang tepat, sehingga kesalahan dalam mengenakan pakaian dapat dihindari. Setiap tahap disusun secara berurutan melalui task analysis dan diukur dalam discrete categorization. Pemberian prompt di setiap tahapannya juga mempermudah anak untuk menguasai tahapan yang diperlukan dalam mengenakan pakaian secara mandiri. Penguatan sosial yang diberikan setiap kali anak menyelesaikan satu tahapan juga memicu anak untuk menguasai tahapan-tahapan tersebut. Penelitian ini menggunakan desain kasus tunggal. Hanya ada 1 partisipan yang terlibat dalam penelitian ini. Kriteria partisipan dalam penelitian ini adalah anak usia 6-10 tahun dengan disabilitas intelektual yang masuk dalam kategori sedang. Berdasarkan hasil pengukuran baseline setelah intervensi dilakukan, ditemukan peningkatan kemampuan memakai baju kaus. Sampel dipilih dengan metode purposive sampling. Secara umum, forward chaining dapat meningkatkan keterampilan anak untuk memakai pakaian secara mandiri, namun terdapat beberapa keterbatasan anak dengan disabilitas intelektual yang perlu mendapat perhatian khusus dalam penerapan intervensi ini.
\end{abstract}

Kata kunci: behavior modification, forward chaining, disabilitas intelektual, dressing skill

\section{PENDAHULUAN}

\section{Latar Belakang}

Anak dengan disabilitas intelektual tidak hanya memiliki keterbatasan dalam aspek kognitif, namun juga memiliki fungsi adaptif (keterampilan bina diri, perilaku sosial, kemampuan komunikasi, kemampuan akademis dan perilaku dalam bekerja) yang lebih rendah dibandingkan dengan anak seusianya (American Psychiatrist Association, 2013). Pada anak dan remaja dengan disabilitas intelektual, penguasaan keterampilan bina diri merupakan komponen penting yang harus dikuasai oleh anak (Beirne-Smith, et. al., dalam Wick-Nelson \& Israel, 2015). Anak yang tidak dapat memperhatikan kebutuhan dasarnya sendiri akan sulit untuk berpartisipasi dalam aktivitas sosial secara mandiri. Kebutuhan dasar umumnya berupa kebutuhan untuk makan dan memakai pakaiannya tanpa bantuan orang disekitarnya (WickNelson \& Israel, 2015).

Sewell, Collins, Hemmeter, \& Schuster, (dalam Lee, Muccio, \& Osborne, 2014) juga mengungkapkan pentingnya kemampuan memakai pakaian bagi anak-anak, terutama anak dengan disabilitas. Mengajarkan keterampilan memakai baju bagi anak-anak adalah hal yang penting, karena keterampilan ini bersifat fungsional, dilakukan dalam aktivitas/rutinitas seharihari, dan memiliki derajat validitas sosial yang tinggi. Umumnya seorang anak membutuhkan 
waktu empat tahun untuk belajar memakai pakaiannya secara mandiri (Shepherd, dalam Weichman, 2012). Anak mempelajari kemampuan mengenakan dan melepas pakaian secara bertahap sejak usia satu tahun (Weichman, 2012).

Keterampilan untuk mengenakan dan melepas pakaian, diperlukan berbagai kemampuan yang harus dikuasai anak, seperti koordinasi motorik kasar dan motorik halus, kesadaran akan posisi tubuh, diskriminasi kanan dan kiri, stabilitas postur tubuh, dan perencanaan motorik (Weichman, 2012; Lee, et. al., 2014). Anak dengan keterbatasan tersebut akan mengalami kesulitan dalam memilih, menggunakan, dan mengatur pakaiannya. Termasuk di dalamnya kesulitan untuk menentukan kiri dan kanan, depan dan belakang. Anak dengan kemampuan kogntif yang terbatas juga akan kesulitan dalam menguasai urutan cara mengenakan pakaian dengan baik dan benar (Lee, et. al., 2014). APA (2013) menuliskan bahwa anak dengan disabilitas intelektual kategori ringan dan sedang mampu menguasai keterampilan bina diri sederhana (seperti mengenakan pakaian) secara mandiri.

Metode yang tepat diperlukan agar anak dengan disabilitas intelektual dapat menguasai kemampuan mengenakan pakaian secara mandiri. Weber (dalam Lee, et. al., 2014) mengatakan bahwa chaining merupakan teknik yang efektif dalam mengajar anak dengan disabilitas intelektual. Behavior chaining adalah teknik modifikasi perilaku yang melibatkan stimulus dan respon yang berurutan secara sistematis, di mana respon terakhir diikuti oleh pemberian penguatan/reinforce. Dalam behavior chaining, target perilaku akan dibagi ke dalam beberapa tahap sehingga anak tidak perlu menguasai satu keterampilan dalam satu waktu. Behavior chaining sendiri terbagi dalam tiga metode, yakni total-task presentation, backward chaining, dan forward chaining (Martin \& Pear, 2015).

Ketiga metode behavior chaining memiliki fungsi dan penerapan yang berbeda-beda. Dalam total-task presentation anak mendapatkan penguatan setelah selesai melakukan seluruh tahap yang harus dilakukan (Martin \& Pear, 2015). Dalam forward chaining, anak diminta untuk menyelesaikan tahap demi tahap secara berurutan, setelah anak berhasil menyelesaikan satu tahap, anak mendapatkan penguatan. Metode ini akan sangat menolong anak dengan yang memiliki kesulitan untuk mempelajari hal secara umum. Metode backward chaining sangat sesuai untuk dilakukan pada anak yang memiliki batas toleransi terhadap frustasi yang rendah, dan memiliki self-esteem yang buruk. Dalam backward chaining, anak diminta untuk melakukan tugas dimulai dari tahapan yang paling akhir. Tahap-tahap sebelumnya dilakukan oleh pengasuh. Anak yang berhasil menyelesaikan satu tahap berhak mendapat penguatan (Case-Smith, dalam Lee, et. al., 2014). Metode forward dan backward chaining memberikan hasil yang efektif bagi perkembangan kemampuan anak dengan disabilitas intelektual. Keduanya memiliki efektivitas yang lebih tinggi daripada metode total-task presentation (Watters; Watters \& Scott, dalam Lee, et. al., 2014).

Penelitian yang dilakukan Batra dan Batra (2006) menemukan bahwa tidak terdapat perbedaan hasil yang signifikan antara penggunaan forward chaining dan backward chaining dalam melatih keterampilan dressing skill pada anak dengan disabilitas intelektual. Hal yang sama ditemukan juga pada penelitian Lee, et. al. (2014), teknik chaining terbukti efektif dalam meningkatkan keterampilan dressing skill pada anak dengan disabilitas intelektual sedang. Teknik chaining merupakan bagian dari intervensi modifikasi perilaku. Salah satu karakteristik penting dalam intervensi modifikasi perilaku adalah penekanan pada perilaku spesifik yang menjadi fokus perubahan. Perilaku harus jelas (overt) dan dapat diukur (Kazdin, 2013). Target perilaku yang dituju dalam penelitian Batra dan Batra (2006) adalah perilaku memakai kaus kaki dan mengikat tali sepatu, sedangkan dalam penelitian Lee, et. al. (2014) target perilaku 
yang dituju adalah perilaku memakai jaket dan celana. Dalam penelitian ini, target perilaku yang akan dikembangkan adalah keterampilan mengenakan baju kaus. Baju kaus dipilih karena merupakan pakaian yang paling sering digunakan anak dalam hidup sehari-hari. Penelitian ini dibuat untuk melihat apakah intervensi modifikasi perilaku dengan teknik forward chaining yang disertai dengan pemberian prompt dan penguatan positif dapat meningkatkan kemampuan memakai baju kaus pada anak penyandang disabilitas intelektual dengan tingkat keparahan sedang.

\section{METODE PENELITIAN}

\section{Partisipan}

Penelitian ini dilakukan terhadap Y, seorang anak perempuan berusia 8 tahun 2 bulan. Ia mendapat diagnosa disabilitas intelektual dengan tingkat keparahan sedang (moderate) pada usia 7 tahun. Ibu menceritakan bahwa Y masih mengalami kesulitan dalam melakukan aktivitas bina diri sehari-hari, salah satunya adalah kesulitan untuk mengenakan pakaian sendiri. Hal ini dikarenakan Y belum dapat membedakan sisi depan dan sisi belakang baju. Ibu seringkali memberikan instruksi secara verbal agar Y dapat mengenakan bajunya sendiri tanpa terbalik, namun Y dinilai kurang dapat memahami instruksi yang diberikan oleh ibu. Akhirnya seringkali Ibunya membantu memakaikan baju secara langsung.

\section{Desain penelitian}

Penelitian ini menggunakan merupakan single-subject experimental design. Single-subject experimental design merupakan metodologi ilmiah yang digunakan untuk menggambarkan prinisip dasar perilaku dan menegakkan kesimpulan berdasarkan bukti ilmiah (Horner, et. al., 2005). Penggunaan subyek tunggal memudahkan peneliti untuk mengendalikan hal-hal yang dapat mengurangi validitas internal dari sebuah eksperimen (Martella, Nelson, \& MarchandMartella, dalam Horner, et. al., 2005). Horner, et. al. (2005) mengungkapkan bahwa Singlesubject experimental design dapat digunakan untuk menganalisis perubahan variabel terikat (umumnya berupa perilaku) yang mendapat paparan sistematik atau manipulasi dari variabel bebas (umumnya berupa intervensi). Tipe Single-subject experimental design dalam penelitian ini adalah the withdrawal design (ABA design). ABA design dimulai dari fase baseline (A), kemudian diikuti oleh fase intervensi (B), dan efek manipulasi variabel terikat dapat dilihat dengan mengulang fase baseline (A) untuk yang kedua kalinya (Byiers, Reichle, \& Symonsa, 2011).

\section{Setting dan peralatan penelitian}

Intervensi dilakukan di rumah tinggal $\mathrm{Y}$ yang berlokasi di Jakarta Utara. Ruang yang dipergunakan untuk intervensi ini adalah ruang keluarga yang terletak di depan kamar mandi tempat Subyek Y mandi. Perlengkapan yang digunakan dalam intervensi ini adalah baju kaus yang memiliki gambar hanya di bagian depan baju. Baju kaus yang digunakan tidak berkancing ataupun dengan ristleting. Baju kaus akan disediakan ibu di meja kecil yang ada di dalam ruangan tersebut. Perlengkapan lain yang digunakan adalah alat tulis dan checklist task analysis dari perilaku memakai baju kaus.

\section{Prosedur Penelitian}

\section{Task analysis}

Melatih kemampuan bina diri pada anak dengan kebutuhan khusus seringkali harus dijabarkan ke dalam tahap-tahap kecil. Tahap pertama untuk melatih kemampuan bina diri anak dengan kebutuhan khusus adalah membuat task analysis (Webster, 2017). Task Analysis adalah pembagian perilaku spesifik yang menjadi target modifikasi perilaku ke dalam tahap-tahap 
konkrit yang berurutan (Kazdin, 2013). Tahapan yang akan dilatih dalam intervensi ini adalah (1) Mengambil pakaian yang disiapkan, (2) Melebarkan baju yang dilipat, (3) Melihat gambar di bagian depan baju, (4) Membalikkan pakaian, (5) Menggulung bagian badan baju sampai ke bagian leher, (6) Memasukkan kepala ke lubang leher, (7) Menunduk dan melihat gambar di bagian depan baju, (8) Memasukkan lengan kanan di lubang lengan, (9) Memasukkan lengan kiri di lubang lengan, dan (10) Menurunkan baju di bagian badan.

\section{Teknik pengukuran}

Teknik pengukuran yang akan diterapkan adalah discrete categorization. Discete categorization sangat berguna untuk mengelompokkan respon dalam kategori terpisah, seperti benar-tidak benar, dilakukan-tidak dilakukan, pantas-tidak pantas. (Kazdin, 2013). Perilakuperilaku yang diukur dalam discrete categorization ini adalah urutan perilaku-perilaku yang disusun dalam task analysis.

\section{Baseline}

Pengambilan baseline perilaku mengenakan baju kaus pada subyek Y dilakukan sebanyak 4 sesi dalam 2 hari. Setiap harinya dilakukan 2 sesi pengambilan baseline. Sesi pagi dilaksanakan sekitar pukul 08.30 - 09.00 dan sesi siang dilaksanakan pukul 15.30-16.00 disesuaikan dengan waktu mandi pagi dan mandi sore $\mathrm{Y}$.

\section{Intervensi}

Intervensi diberikan di dalam 8 sesi dalam 4 hari. Setiap Setiap harinya dilakukan 2 sesi intervensi. Sesi pagi dilaksanakan sekitar pukul 08.30-09.00 dan sesi siang dilaksanakan pukul 15.30-16.00 disesuaikan dengan waktu mandi pagi dan mandi sore Y. Dalam program intervensi, Y akan diajarkan untuk memakai baju kaus secara bertahap, sehingga ia dapat mengenakan bajunya dengan benar tanpa terbalik. Untuk mengarahkan tahapan perilaku yang harus ditampilkan, Y akan mendapat prompt. Prompt hanya diberikan pada 6 sesi pertama dalam intervensi. Pada sesi 7 dan 8 prompt tidak lagi diberikan. Setelah Y berhasil menyelesaikan 1 tahap, Y akan mendapat penguatan positif berupa pujian "Kamu Hebat", dan tos dengan peneliti.

\section{Baseline}

Pengambilan baseline kedua dilakukan setelah intervensi diberikan. Pengukuran baseline dilakukan kembali sebanyak 4 sesi dalam 2 hari. Setiap harinya terdiri dari 2 sesi pengambilan baseline. Sesi pagi dilaksanakan sekitar pukul 08.30 - 09.00 dan sesi siang dilaksanakan pukul 15.30-16.00 disesuaikan dengan waktu mandi pagi dan mandi sore Y.

\section{Maintenance}

Maintenance perlu dilakukan agar perilaku baru yang sudah dibentuk dalam intervensi dapat dipertahankan. Teknik maintenance yang dipilih dalam penelitian ini berupa adult facilitator dimana orangtua akan mengawasi dan mempertahankan pemberian penguatan positif saat $\mathrm{Y}$ dapat mengenakan bajunya sendiri tanpa terbalik.

\section{HASIL DAN PEMBAHASAN}

Berdasarkan hasil pengukuran baseline pada Tabel 1, dapat dilihat bahwa Y dapat melakukan 5-6 tahap dari 10 tahap yang harus dilakukannya. Perilaku yang kerap terlewat adalah perilaku melihat gambar di bagian depan baju, membalikkan pakaian, menggulung bagian badan baju sampai ke bagian leher, dan menunduk dan melihat gambar di bagian depan baju. Jika diperhatikan beberapa tahap yang dilewatkan oleh $\mathrm{Y}$ adalah tahap di mana seseorang 
menentukan sisi depan dan sisi belakang bajunya. Y memakai bajunya tanpa memperhatikan sisi depan dan sisi belakang baju, sehingga tidak mengherankan jika ia seringkali memakai bajunya dengan terbalik. Keempat perilaku tersebut terlewat secara konsisten di 4 sesi penghitungan baseline sehingga program intervensi dapat dilakukan.

Pemberian intervensi dilakukan dalam 8 sesi. Pada 5 sesi pertama, Y diberikan arahan untuk masing-masing tahap melalui prompt. Setelah diberikan prompt, Y dapat melakukan hampir seluruh tahapan yang diberikan. Ia dapat mengikuti arahan yang diberikan, dan mendapatkan penguatan berupa pujian dan tos. Hanya satu tahapan yang terlewat saat prompt diberikan, yakni tahap menggulung bagian badan baju sampai ke bagian leher. Gerak motorik halus yang baik diperlukan dalam menguasai tahap ini. Sulitnya Y melakukan tahapan tersebut disebabkan oleh keterbatasan motorik halus yang dimiliki oleh Y. Anak dengan disabilitas intelektual juga kerap mengalami keterbatasan motorik, baik motorik kasar maupun motorik halus (Pratt \& Greydanus, 2007). Setelah prompt dihilangkan, perilaku melihat gambar di bagian depan baju, membalikkan pakaian, dan menggulung bagian badan baju sampai ke bagian leher kembali dilewatkan oleh Y.

Pada tahap pengambilan baseline yang kedua, beberapa perilaku yang terlewat setelah prompt tidak lagi diberikan kembali terlewat. Jika diberikan prompt secara bertahap, Y mampu menampilkan perilaku yang diminta. Jika prompt tidak diberikan, beberapa perilaku yang mampu dilakukan sebelumnya kembali terlewat. Hal ini dipengaruhi keterbatasan kognitif Y, yang mempengaruhi kecepatan $\mathrm{Y}$ dalam mempelajari hal baru (American Psychiatrist Association, 2013). Jika dilihat secara umum kemampuan Y dalam memakai baju kaus mengalami peningkatan. Setelah intervensi dilakukan, Y mampu menguasai 7 tahap dari 10 tahap yang diperlukan untuk memakai baju kaus tanpa terbalik. Sekarang Y mampu menunduk dan melihat gambar di bagian depan baju, sehingga ia dapat menemukan bagian baju yang bergambar untuk diposisikan di bagian depan. Hal ini membuktikan bahwa teknik forward chaining yang disertai dengan pemberian prompt dan penguatan sosial dapat meningkatkan kemampuan memakai baju Y. Hasil dalam penelitian ini sejalan dengan penelitian-penelitian sebelumnya yang menemukan bahwa forward chaining dapat meningkatkan kemampuan dressing skill anak dengan disabilitas intelektual (Batra \& Batra, 2006; Lee, et. al., 2014). 
Tabel 1

Hasil Pengukuran Baseline, Intervensi, dan Baseline setelah Intervensi.

No. Perilaku Baseline

Pelatihan

Baseline

Dengan Prompt Tanpa Prompt

1. Mengambil pakaian yang disiapkan

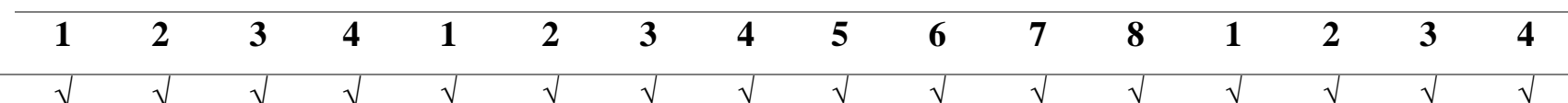

2. Melebarkan baju yang dilipat

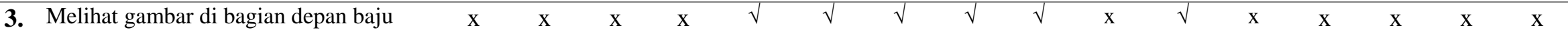

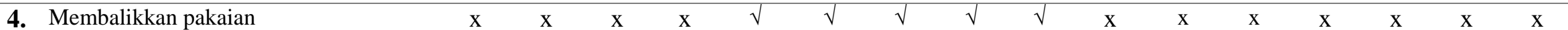

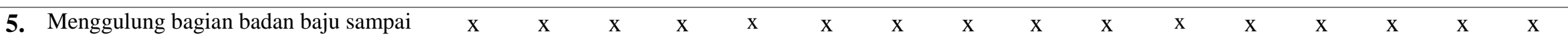
ke bagian leher

6. Memasukkan kepala ke lubang leher

7. Menunduk dan melihat gambar di bagian depan baju

8. Memasukkan lengan kanan di lubang lengan

9. Memasukkan lengan kiri di lubang lengan

10. Menurunkan baju di bagian badan 


\section{KESIMPULAN DAN SARAN}

Intervensi modifikasi perilaku dengan teknik forward chaining yang disertai dengan pemberian prompt dan penguatan positif dapat meningkatkan kemampuan memakai baju kaus pada anak dengan disabilitas intelektual sedang. Setelah diberikan intervensi kemampuan Y dalam memakai baju kaus mengalami peningkatan, walaupun belum semua tahapan dapat dikuasai oleh Y. Terutama pada tahap menggulung bagian badan baju hingga ke leher belum dapat dilakukan karena keterbatasan motorik halus Y.

Penelitian ini juga masih memiliki beberapa keterbatasan, sehingga peneliti memberikan beberapa saran untuk penelitian selanjutnya. Pertama, mengingat keterbatasan anak dengan disabilitas intelektual sedang dalam mempelajari hal baru, sebaiknya pemberian intervensi dapat dilakukan dengan sesi yang lebih banyak. Kedua, lebih memperhatikan jenis penguatan yang diberikan, sebaiknya penguatan tidak hanya diberikan dalam bentuk penguatan sosial namun juga diberikan dalam bentuk nyata (seperti hadiah kecil atau gambar tempel). Penguatan sosial jika diberikan secara bersamaan dengan tangible reinforcement akan memberikan efek penguat yang lebih besar (O’Leary, Poulos, \& Devine, 1971). Ketiga, untuk dapat menggeneralisasi hasil penelitian ini pada populasi anak dengan disabilitas intelektual, penelitian selanjutnya diharapkan menggunakan jumlah sampel yang lebih besar.

\section{Ucapan Terima Kasih}

Saya mengucapkan terima kasih kepada Y dan keluarga atas kesediaannya untuk menjadi partisipan penelitian ini, mengikuti setiap prosesnya, dan memberikan izin untuk menjalankan intervensi di kediaman mereka. Secara khusus saya juga berterimakasih kepada Ibu $\mathrm{Y}$ yang berpartisipasi aktif di dalam proses intervensi maupun dalam maintenance setelah intervensi dihentikan.

\section{REFERENSI}

American Psychiatric Association. (2013). Diagnostic and statistical manual of mental disorders (5th ed). Arlington, VA: American Psychiatric Association.

Byiers, B. J., Reichle, J., \& Symons, F. J. (2012). Single-subject experimental design for evidencebased practice. American Journal of Speech-Language Pathology, 21, 397- 414.

Horner, R. H., Carr, E. G., Halle, J., McGee, G., Odom, S., \& Wolery, M. (2005). The Use of Single-Subject Research to Identify Evidence-Based Practice in Special Education. Exceptional Children, 71 (2). https://doi.org/10.1177/001440290507100203

Kazdin, A. E. (2013). Behavior modification in applied settings (7th ed.). Illionis: Waveland Press, Inc.

Lee, S. C., Muccio, B., \& Osborne, N. L. (2009). The effect of chaining techniques on dressing skills of children with moderate mental retardation: A single-subject design study. Journal of Occupational Therapy, Schools, \& Early Intervention, 2(3-4), 178-192. doi:10.1080/19411240903392590

Martin, G. \& Pear, J. (2010). Behavior modification :What is it and How to do it (9 th ed.). USA : Pearson Education, Inc.

O’Leary, K. D., Poulos, R. W., \& Devine, V.T. (1971). Tangible reinforcers: Bonuses or bribes? In A. M. Graziano. (Eds.) Behavior therapy with children. Chicago, IL: Aldine-Atherton

Pratt, H. D., \& Greydanus, D. E. (2007). Intellectual disability (mental retardation) in children and adolescents. Primary Care, 34, 375-386. 
Weichman, L. (2012, November 9). Dressing skills: Developmental steps for kids. Retrieved from https://nspt4kids.com/therapy/dressing-skills-developmental-steps-for-kids/ 